\section{OCCURRENCE IN HUMAN SERUM OF YELLOW SUBSTANCES DIFFERENT FROM BILIRUBIN}

\author{
By DR. TORBEN K. WITH
}

Medical Department A, Rigshospital, Copenhagen.

$\mathrm{T}$ HE yellow colour of human serum is generally assumed to be caused mainly by bilirubin. The bilirubin concentration can be determined by means of the dia\% reaction as modified by Jendrassik and Gróf $^{1,2}$. By the addition of pure bilirubin to serum, I was able to demonstrate that the proportion diazo reaction/yellow colour in human serum varied within narrow limits; if both are measured in the Pulfrich photometer, the diazo reaction with the filter $S .61^{1}$ and the yellow colour with $S .43^{3}$, the proportion between the extinctions $(E .61 / E .43)$ varies between $1 \cdot 38$ and 1.60 (average 1.455 ); twenty-five human sera poor in bilirubin to which pure bilirubin was added were investigated ${ }^{4}$.

Measurements of E.61/E.43 in human sera without addition of bilirubin showed great variation, and for most sera values below the lower limit $(1 \cdot 38)$ for pure bilirubin added to serum. My measurements on twenty-eight normal and thirty-one icterie sera are presented in the accompanying diagram, in which three lines are drawn corresponding to the limits and average $(1.38,1.60$ and 1.455$)$ of the proportion $E .61 / E .43$ for bilirubin added to serum. The diagram shows that most of the sera have considerably more yellow colour than that corresponding to their diazo reaction. This may be due to the presence of yellow substances other than bilirubin, or to partial reaction only of their bilirubin with the diazo reagent; but with the technique used the latter cannot be true ${ }^{4}$, and consequently yellow substances different from bilirubin (yellow non-bilirubin) must be present.

A quantitative expression of the yellow nonbilirubin content of a serum may be obtained from the diagram by drawing a vertical line through the point corresponding to the serum in question (defined by its diazo and yellow extinctions). The distance from this point to the point of intersection between the vertical line and the line in the diagram symbolizing the average value of $E .61 / E .43$ corresponds to the yellow non-bilirubin extinction, and the distance from the point of intersection of the vertical line and the E.61/E.43 line to the point of intersection of the vertical line and the abscissa corresponds to the

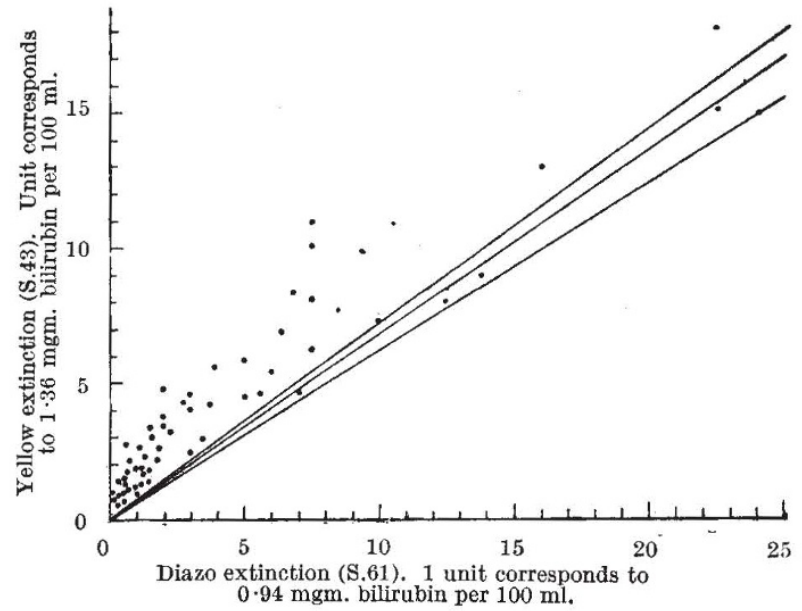

yellow extinction of the bilirubin present in the serum. The yellow units of the diagram correspond to $1.36 \mathrm{mgm}$. bilirubin each. From the diagram it is seen that in most normal sera (diazo extinction less than 2) the yellow non-bilirubin extinetion is considerably greater than the yellow bilirubin extinction, and in some icteric sera also this is the case.

The chemical nature of the yellow non-bilirubin is not sufficiently known. The carotenoids have to be taken into account, but as the total serum carotenoids -measured as $\beta$-carotene-in European populations show concentrations only as low as 10-50 $\gamma$-and seldom above $100 \gamma$-per $100 \mathrm{ml}$. serum ${ }^{5,6,7}$, it can be calculated that their extinction with $S .43$ in most cases is less than $0 \cdot 1$ of our yellow extinction units $^{3}$, and as the yellow non-bilirubin concentration most often is greater than 0.5 yellow units (ef. the diagram) the carotenoids can only form a minor part of the yellow non-bilirubin and in most cases an insignificant one.

For biliverdin it is known that its absorption at $660 \mathrm{~m} \mu$ is three to six times that at $430 \mathrm{~m} \mu$, varying with the solvent ${ }^{8}$. The 660 -extinction of fifteen normal and ten icteric sera was measured with filter $S .66$ in the Pulfrich photometer and compared with their yellow non-bilirubin extinction, and the fraction E.66/E.43 varied between 0.07 and $1 \cdot 10$ (average $0 \cdot 325$ ) ; as biliverdin shows the value $3-6$ for this fraction, only a small part of the yellow non-bilirubin can consist of biliverdin.

Other substances which may form a part of the yellow non-bilirubin are the pyrrol compounds bilifuscin and mesobilifuscin ${ }^{9,10}$, which are formed from myoglobin by a process parallel to the formation of bilirubin from hæmoglobin, and according to Engel $^{11}$ are also formed during the normal disintegration of hæmoglobin. Further, the so-called xanthorubin, a yellow compound present in the serum of hepatectomized dogs in greater concentration than bilirubin itself $12,13,14$, should be considered in this connexion.

As strongly icteric sera generally show yellow non-bilirubin extinctions producing only small fractions of their bilirubin extinctions (cf. diagram), it may be concluded that the elimination of yellow non-bilirubin from the organism must take place chiefly by other means than the liver and bile; further, as the serum in uræmia is not more yellowcoloured than normal serum, the kidneys cannot play any part in its elimination.

The isolation of yellow non-bilirubin for further study will be a difficult task, as its concentration in the serum at the most amounts to $c .6$ extinction units, corresponding to $c .8 \mathrm{mgm}$. bilirubin per 100 ml. of serum.

'Jendrassik, L., and Gróf, P., Biochem. Z., 297, 81 (1938).

a Jendrassik, L., and Gró, P., Biochem. Z., 297, 81

${ }^{3}$ With, 'T. K., Acta med. scandinav., 122, 501 (1945).

"With, T. K., Acta physiol scandinav. 10, 172 and 182 (1945)

${ }^{5}$ With, T. K "Absorption, Metabolism and Storage of Vitamin A and Carotene" (Monograph. E. Munksgaard, Copenhagen, and

6 With, T. K., Vitamine und Hormone, 1, 429 (1941).

Engel, A., Granström, K. O., Lindgren, I., and Norlander, N. Tid. Mil. Hälsovard' (Stockholm), 67, 157 (1942)

${ }^{8}$ Lemberg, K., and Barcroft, J., Proc. Roy. Soc., B, 110, 362 (1932). Meldolesi, G., Siedel, W., and Möller, H., Z. physiol. Chem., 259 $137(1939)$.

${ }^{10}$ Siedel, W., and Möller, H., Z. physiol. Chem., 259, 113 (1939).

11 Engel, M., Z $Z$. physiol. Chem., 266, 135 (1940).

Melchior, E., Rosenthal, F., and Licht, H., Arch. exp. Path. $u$. Pharm., 107, 238 (1925).

${ }^{13}$ Enderlen, E., Thannhauser, S. J., and Jenke, M., Arch. exp. Path. u. Pharm., 120, 16 (1927).

14 Fiessinger, N., and Gajdós, A., C.R. Soc. Biol. Paris, 110, 455 (1932). Fiessinger, N., Palmer, R. G., and Lancon, R., ibid., 110, 454 (1932). 